\title{
The Author Replies: On the Subject of Subjectivity
}

Sandra G. Kouritzin

While writing, struggling to help my thoughts gain expression, I often wonder if what I have to say will ever be read by anyone other than captive graduate students working on a related topic. I have, therefore, been delighted to have the opportunity to respond to $\mathrm{Li}$ (in press), and to have a conversation with her in print, knowing that a colleague read what I wrote, interacted with the text, and felt strongly enough about our practice as researchers and teachers to draw our attention to the nature of subjectivities and the different ways of positioning ourselves in our profession. In line with the native-speaker teacher-non-native speaker teacher discussion that is ongoing in the TESOL Quarterly, the TESL Canada Journal, and other locations, I would like to think that perhaps $\mathrm{Li}$ and I are beginning a conversation about native-speaker researchers in TESL, and non-native speaker researchers in TESL, that will invite many voices from many positions-or perhaps I should say, many subjectivities.

As I understand from her response, Li concludes that I have not addressed the issue of the researcher's subjectivity in my article. She argues, convincingly, that knowledge of researcher subjectivity is a particularly important aspect of life history research, given that narrative inquiry is fundamentally an exercise in subjectivity. Locating her argument in an influential and cutting-edge body of literature, Li maintains that subjectivity determines the nature of the relationship between the researcher and the researched and that it therefore influences both the interpretation and representation of the life history's narrative "truth." I am in complete agreement with Li's point; however, I feel that my omission is better characterized by the words insufficient attention than by such words as "not addressed," "not included," and "not touched on," "disguises the unequal power relationship," or "denying the existence of the predispositions and assumptions."

After carefully explaining her argument, $\mathrm{Li}$ then suggests that the researcher's knowledge and awareness of subjectivity can empower both the researcher and the researched to "work toward social change-at both theoretical and individual levels." I have tried to view this argument from many angles, but at the moment I set pen to paper, I remain somewhat less in agreement with this point. I remain open to Li's suggestion, and I would 
welcome the opportunity to discuss her argument further, but at this time I am not someone who can make this kind of argument comfortably.

Inow address the first of Li's concerns. Reading her response to my article sent me on a scavenger hunt through my bookshelves, looking at the field notes and transcripts, journal writings and "analytic memos" (Delamont, 1992, p. 151) that are the artifacts of my life history research projects. Comparing these with the published accounts of my research (Kouritzin, 1999, 2000c) reassured me that $I$ had tried to pay attention to my own researcher subjectivities in the "doing," the interpreting, and the writing and representation of other people's life histories. Indeed, in a recent review of my book containing five life histories, Mann (2000) wrote "Sandra Kouritzin put so much of herself into the book that I feel that I knew her and that we are on a first-name basis. Choosing the style of research that she did allowed her to become one of the faces that I touched as a read this book" (p. 117). In my autobiographical work (Kouritzin, 2000b, in press), I have been as open about the subjective nature of my intellectual positioning(s) as possible, without actually forcing readers into the posture of voyeurism. In my life history research, both autobiographical and biographical, I realize that I could have been more thorough-more ready to unpack my "ideological baggage" (Li), more able to identify, question, and deconstruct my power and position in the research relationships-but on the other hand, how much reflexivity is enough? At what point does reflexivity lead us into ego ethnography rather than intellectual integrity? Granted it is likely that at this point of my life I would have viewed a different "truth," represented it differently, and deconstructed my own position in a different manner-but I am a different person now than then; the personal, social, geographic, and professional circumstances of my life have altered, and my multiple shifting subjectivities are located in different frames of reference. Still, it seemed illogical that I would have struggled with awareness of my positionality, striven to juxtapose my realities with those of "the researched," but then failed to consider researcher subjectivity in my article describing life history, and advocating inclusion of life history narrative knowledge in our participation in what is basically an act of colonialism.

In my article (Kouritzin, 2000a), I speak often of the nature of researcher subjectivity and her or his responsibility to the research context. I argue that the nature of being human makes us "all social scientists, understanding others in terms of those narrated biographical 'chunks' to which we are privy, and then curling, intertwining our lives within and among them" (p. 2). I describe my life history research process, explaining that I not only struggle with my subjectivity, but I try, before beginning the process of negotiating consent, to share "my own biases and investment in the project, the procedure I would follow in each interview, the uses of the data, the considerable time commitment, the nature of our relationship, and what they 
could expect from me" (p. 6). Also in the description of my methodological processes, I explain that "I made no pretense that we were having "conversations,' but rather explained my own understanding of the word interoiew, a word that I see as capturing the notion of a negotiated space between two people, one requiring effort from the narrator and the listener" (p.3), and one well represented by a translation of its Japanese characters, "face-touching." In a footnote to this argument, I state that the word conversations implies that the conversants have equal power relationships and equal conversational responsibility, whereas in a life history interview, the researcher controls the social conventions and the context and is responsible for managing the flow of dialogue.

Later in the article I argue that "engaging in life history research encourages reflexivity and a holistic concept of the self and others" (p. 22), and I quote Fine's (1994) position that "when we look, get involved, demur, analyze, interpret, probe, speak, remain silent, walk away, organize for outrage, or sanitize our stories, and when we construct our texts in or on their words, we decide how to nuance our relations with/for/despite those who have been Others" (pp. 74-75). I further Fine's position, by suggesting that while

we are able to, and should, speak of our own investment in the research project, our trials and errors, our experiences ... we need to remain cognizant that this practice does not eliminate, or even diminish, the possibility of misinterpretation. It does, however, enable polished readers to locate us; it places us at risk (at equal risk if we have done our work well); it allows readers to gain a sense of our professional and personal integrity; and it acknowledges the layers of experience that render a text. (Kouritzin, 2000a, pp. 28-29)

In other words, I argue that reflexivity and awareness of researcher subjectivity does not mean that we produce better, or even less damaging research, better, or less damaging texts.

I go on to warn that ethical principles as outlined by various institutional guidelines (such as university ethical review procedures or the Tri-Council ethical guidelines) is not enough in life history research (p. 29), and caution that life history should never be entered into with "any pretense to objectivity" (p. 29). Indeed, I make the same argument $\mathrm{Li}$ does, though less categorically, when she states that "denying the existence of the predispositions and assumptions will result in the distortion of narrative truth and reality - and further stereotyping of the disadvantaged." My own way of stating this reads: "entering a life history relationship stripped of our own subjectivities may nullify the benefits for the participants, and indeed put them at far greater personal and psychological risk than they would face in other kinds of research" (p. 29). 
Finally, in the conclusion to my article I state that life histories demand from the researcher "greater reflexivity, more critical awareness of the role of the researcher, a commitment to social responsibility, and acknowledgment of one's own participation in an imperialistic enterprise" (p. 30). I conclude that the life history is "not the only methodology that leads researchers to acknowledge their assumptions, but it may be the only one that does so inherently" because when the life history narrator begins a story "and that story winds itself through the a priori categories of the researcher, race, class, language, culture, and history are bound together in multifarious ways that do not lend themselves easily to homogenous description" (p. 30).

But if the question reads not "have you addressed this point?" but rather "have you done enough?" my answer becomes more slippery. There were many roads I could have gone down in writing the article "Bringing life to research: Life history research and ESL," but I chose to focus on what the title implied, meaning how the knowledge generated by life history research can augment "business as usual" in ESL research. Perhaps another writer would have given "subjectivity of the researcher" its own subtitle and section in the article instead of weaving the idea into the text of the article. Perhaps another writer would have given more attention to the analysis of, and representation in, life history research, topics that I have largely left for an article I am now revising and hope to be able to share in the future. Particularly given that this article spans over 30 pages, perhaps I have not devoted sufficient attention to the multiple shifting subjectivities of the life history researcher, and the proof of this accusation is that Li read my article carefully, thoughtfully, and respectfully, and yet she felt that I had been remiss. I certainly do not give this topic the careful time or attention that Li does, making hers an important corollary to my original text.

Li moves from a thoughtful consideration of researcher subjectivity to a position that I find more controversial, that is, that "recognizing one's subjectivity in ESL life history will not only benefit the researcher, but also more importantly, empower the researched to take actions to improve their conditions." She later refers to this phenomenon as "personal transformation," and identifies life history as "a form of inquiry for social change." This is not a position that I can unreservedly endorse.

I believe that my reservations about Li's assertion stem from the researcher subjectivities that began our conversation. I am a White, Canadianborn woman, married to a man of Ryukyu (one of the indigenous peoples of Japan) heritage. Although I have witnessed his experience of immigrating to Canada, his struggle to claim an identity within rather than outside the margins of Canadian society, his frustration with his powerlessness in a system premised on Western norms, I do not, and cannot, know what it means to be anything but a White Canadian-born, native-English-speaking woman in Canada. I am, therefore, simply not comfortable with the role of 
"empower[ing] the participants to challenge the existing power structure that has shaped their life experiences" (p. 7) because my inability to understand thoroughly from an emic perspective the life experiences of an immigrant makes me an untrustworthy ally in such an enterprise.

To cite an example, in 1997 I was pleased when an entire issue of the TESOL Quarterly was devoted to social power and identity issues in TESL. But I found the article written by Morgan (1997) disturbing. Morgan described teaching a class on intonation, during which students from Hong Kong discussed the unequal power relationships in a fictitious Chinese family's home, especially when the wife wanted to take English classes and her husband was opposed. I (and a group of graduate students) felt that Morgan had been blinded by his commitment to being a catalyst for social change and personal transformation, and he had therefore ventured into forbidden territory. He asks the question "Will my students use their new understanding of ESL intonation to resist or challenge the roles ascribed to them in their family, particularly as family life in Canada undergoes transformation?" (p. 446), and his response is both "yes" and "no." His argument is that immigrant families are unlikely to negotiate change in the English language, but he feels the lesson was "relevant to broader communication patterns in immigrant families" (p. 447). Morgan goes on to write that "our ESL classroom provided students with an opportunity to share their personal difficulties, evaluate them against the experiences of others, and begin to recognize them as socially constructed and potentially transformed through social action" (p. 447). Had Morgan worked with his students toward deconstructing the systemic inequalities in mainstream society, I would not have had misgivings, but I question his intrusion into people's homes. From my point of view, he had not adequately deconstructed his own subjectivities; from my point of view, Morgan is an exemplar of Li's arguments about the dangers of failing adequately to reflect on, and deconstruct, researcher (or teacher) subjectivities. Morgan's point of view, however, appears to differ from mine; I believe that Morgan would present himself as self-aware. Indeed, Morgan concludes,

ESL teachers should pay close if not equal attention to the historical and local conditions that influence identity formation when contextualizing language activities in the classroom. A far more difficult challenge for teachers, however, will be to address their own sociopolitical assumptions inscribed within TESOL's theories and technologies of language acquisition, methodology, and research. (p. 447)

In my reading of these words, Morgan warns readers not to visit their own assumptions on students or on the researched.

My point is this: as someone who belongs to the traditional "mainstream" and the dominant culture of Canada, I am not sure that I can be, should even 
try to be, a responsible agent for the personal transformation of others. I feel that in terms of the ESL learners that I am likely to engage in life history research on/with/for, I need to limit my participation to listening, validating, and giving voice to the researched. If by doing so I become a sounding board for individuals who are then inspired to change the material circumstances of their lives, if they are able to recognize the moments of adversity in their lives and the uses to which overcoming those moments of adversity can be put (Cohler, 1991), then like any researcher working in any paradigm I must live out the consequences of my complicity. But I cannot in the life history research process urge participants to "challenge the existing power structure that has shaped their life experiences" ( $\mathrm{Li}$, in press), because doing so would fail to acknowledge the differential power relationships between me, a White Canadian researcher, and the other, a non-native English-speaking newcomer to Canada. Just by virtue of who I am and what I represent, my opinion carries an imperative force that is likely to be magnified by the research context. That is not to say that I would not express an opinion if asked. But I would leave my opinion open-ended as much as possible, present it as a possibility in a wide range of possibilities, try to present a different (or even opposing) view, and remind the research participant that I am not a counselor, or a social worker, or any sort of authority with the ability to spur social change.

Rather, my role as I see it is to examine the power relationships in the social system that I represent and work within and against people of similar social backgrounds to change the systemic inequalities that exist. In other words, as an exemplar of the dominant culture's power structure, I feel that I cannot empower others; I can only strive to disempower myself and others like me.

Although Li does not position herself in her response to me, I am given to understand from my knowledge of her work that she is able to do research from a different position than I am. The evidence she cites of personal transformation in her work with Chinese immigrant parents, one of whom "realized the significance of learning the English language in her position as a female minority in Canadian society" (p. 7) and who decided to give up a factory job in order to pursue English as a second language study, would if located in my work take on connotations of forced assimilation and cultural imperialism. I could not celebrate her transformation unreservedly, wondering if, however innocently, I had ensured that she adopt my cultural imperatives. I cannot avoid the washback effect of research-indeed, as Li points out, it is often something to celebrate-but I am not sure that personal transformation should be described as a benefit in situations characterized by mainstream researchers working with non-mainstream researched. 


\section{References}

Delamont, S. (1992). Fieldwork in educational settings: Methods, pitfalls, and perspectives. London: Falmer.

Fine, M. (1994). Working the hyphens: Reinventing self and other in qualitative research. In Y. Lincoln \& N.K. Denzin (Eds.), The handbook of qualitative research (pp. 70-82). Thousand Oaks, CA: Sage.

Kouritzin, S. (1999). Face[t]s of first language loss. Mahwah, NJ: Erlbaum.

Kouritzin, S. (2000a). Bringing life to research: Life history research and ESL. TESL Canada Journal, 17(2), 1-35.

Kouritzin, S. (2000b). A mother's tongue. TESOL Quarterly, 34, 311-324.

Kouritzin, S. (2000c). Redefining access: Contradiction and ambivalence. Journal of Multilingual and Multicultural Development, 21(1) 14-32.

Kouritzin, S. (in press). The British Columbia literature 12 curriculum and I: A soliloquy. Curriculum Inquiry.

Li, G. (in press). A conversation with Sandra Kouritzin. TESL Canada Journal.

Mann, P. (2000). Review of Facelt]s of first language loss by Sandra G. Kouritzin. TESL Canada Journal, 17(2), 116-118.

Morgan, B. (1997). Identity and intonation: Linking dynamic processes in an ESL classroom. TESOL Quarterly, 31, 431-450. 